1 In situ measurements of explosive compound dissolution fluxes from exposed munition material in the

2 Baltic Sea

3 Aaron J. Beck ${ }^{1 *}$, Eefke M. van der Lee ${ }^{2}$, Anja Eggert ${ }^{2}$, Beate Stamer ${ }^{1}$, Martha Gledhill ${ }^{1}$, Christian

4 Schlosser $^{1}$, and Eric P. Achterberg ${ }^{1}$

$5 \quad{ }^{1}$ GEOMAR Helmholtz Centre for Ocean Research Kiel

$6 \quad 2$ Leibniz-Institute for Baltic Sea Research Warnemünde

$7 \quad *$ Correspondence: ajbeck@geomar.de

8 Abstract

9 Underwater munitions containing millions of tons of toxic explosives are present worldwide in coastal 10 marine waters as a result of unexploded ordnance and intentional dumping. Dissolution flux of solid 11 explosives following corrosion of metal munition housings controls exposure of biological receptors to 12 toxic munition compounds (MC; including TNT: 2,4,6-Trinitrotoluene, RDX: 1,3,5-Trinitro-1,3,5-triazinane, 13 and DNB: 1,3-Dinitrobenzene). Very little is known about the dissolution behavior of MC in the marine 14 environment. In this work, we exploit a unique marine study site in the Baltic Sea with exposed solid 15 explosives to quantify in situ MC dissolution fluxes using dissolved MC gradients near the exposed 16 explosive surface, as well as benthic chamber incubations. The gradient method gave dissolution fluxes 17 that ranged between 0.001 and 3.2, 0.0001 and 0.04 , and 0.003 and $1.7 \mathrm{mg} \mathrm{cm}^{-2} \mathrm{~d}^{-1}$ for TNT, RDX, and DNB, respectively. Benthic chamber incubations indicated dissolution fluxes of $0.0047-0.277,0-0.11$, and 0.00047-1.45 $\mathrm{mg} \mathrm{cm}^{-2} \mathrm{~d}^{-1}$ for TNT, RDX, and DNB, respectively. In situ dissolution fluxes estimated in the current study were lower than most dissolution rates reported for laboratory experiments, but clearly demonstrated that MC are released from underwater munitions to the water column in the Baltic Sea.

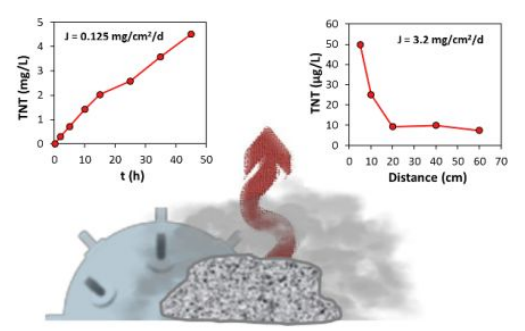


Coastal marine environments are contaminated worldwide with millions of metric tons of dumped munitions and unexploded ordnance ${ }^{1}$. The majority of these underwater munitions were the result of activities during and after the World Wars (WW), especially WWII. As a consequence, coastal waters in Europe, North America, and the southwest Pacific are particularly heavily impacted. Records of munitions disposal are often incomplete or not sufficiently detailed, and the extent and type of munitions present in the coastal ocean is often not well known ${ }^{2,3}$. Underwater munitions represent a major hazard for development of offshore infrastructure such as aquaculture, wind farms, and oil or gas pipelines ${ }^{4-6}$, increasing interest in removal and remediation of marine munitions.

34 In addition to the threat of detonation, many chemical compounds present in explosive materials are cytotoxic, genotoxic, and carcinogenic, and may represent an ecological hazard to marine organisms ${ }^{7,8}$. Undersea munitions may actually act as habitats for marine organisms 9,10 , increasing the likelihood of food web exposure to munition related chemicals. Several studies have documented uptake of munitions compounds by organisms near underwater munitions ${ }^{11-14}$. These chemicals may enter the marine food web, and be present in seafood for human consumption ${ }^{14}$, but the extent of this exposure is not known.

Dissolution of MC from explosive solids represents the initial controlling factor for release into the environment and exposure to ecological receptors. Reported dissolution rates increase rapidly with temperature, doubling with each $10^{\circ} \mathrm{C}$ increase ${ }^{15,16}$. A slight reduction of dissolution rate $(<25 \%)$ has been reported for seawater (salinity 20) compared with fresh water ${ }^{17}$. Dissolution of $\mathrm{MC}$ from explosives

44 solids also depends on formulation, with slowly soluble components such as $\operatorname{HMX}(1,3,5,7-$ Tetranitro- 
48 terrestrial systems, simulations of dissolution by rainfall also show enhanced mass loss under higher flow 49 conditions ${ }^{22}$. This suggests that dissolution rates under environmental conditions may not resemble 50 those measured under ideal laboratory conditions.

51 Numerical oceanographic models can help to scale up dissolution rates to the water body and assess the 52 environmental risk associated with dissolved MC. Some modeling efforts have been successful at

53 describing the release of chemical constituents from breached munitions ${ }^{23}$, but are nonetheless based on

54 laboratory dissolution data (e.g., ${ }^{24}$ ). In order for oceanographic models to reliably simulate the transport

55 and fate of these compounds in the water column, they must be based on kinetic parameters

56 representative of munition compound dynamics in natural marine systems. Although MC dissolution is

57 relatively well-constrained in freshwater under laboratory conditions, there are few data available in

58 high ionic strength solutions or seawater 25,26 , and no in situ measurements whatsoever. This represents a

59 particular weakness in our ability to predict chemical release and spread in marine systems. The purpose

60 of the current work was to exploit the unique presence of exposed munition material at a coastal study

61 site to measure dissolution rates of $\mathrm{MC}$ under in situ conditions. To our knowledge, this is the first

62 attempt to make such field measurements. 
The Kolberger Heide munition dumping ground is located in the southwest Baltic Sea near Kiel, Germany,

67 at approximately $54.4^{\circ} \mathrm{N}$, and $10.3^{\circ} \mathrm{E}$ (Fig. S1). The site has brackish salinity (15-20), and a tidal range of

68 less than $50 \mathrm{~cm}$. Current speeds near the seafloor are slow, typically around $0.04 \mathrm{~m} / \mathrm{s}$ and variable, but

69 generally directed to the south-west. Bottom sediments are medium-coarse sands. The dumping ground

70 is restricted to marine traffic, in an area of approximately 1,260 hectares and 10-15 m deep, located

71 three to five nautical miles off the coast of Germany. The dumpsite was approved for munitions disposal

72 in 1945, and is known to contain both German and British ordnance from World War II4. Some 30,000

73 tons of munitions are present at the site, and are thought to contain material comprising mainly TNT,

74 RDX (1,3,5-Trinitro-1,3,5-triazinane), and DNB (1,3-Dinitrobenzene).

75 Within the Kolberger Heide site, there are clusters of munitions, such as a large pile of approximately 70

76 sea mines ${ }^{27}$, but also more widely scattered ordnance such as ground mines, torpedoes, depth charges,

77 and grenades. Some 6600 munition-like objects were identified on the seafloor during one survey of the

$7825 \mathrm{~km}^{2}$ dumping ground ${ }^{27}$. Between 2009 and 2012, numerous large mines up to $550 \mathrm{~kg}$ in size were

79 intentionally detonated at the site by military explosive ordnance disposal experts (EOD) ${ }^{28,29} . \ln 2009$,

80 several of the mines underwent low-order detonation, which resulted in scattering of intact, exposed

81 explosive material in the water column and on the seafloor ${ }^{28}$. Scientific divers at the site have observed

82 large (meter-scale) piles of exposed explosives, as well as more wide-spread scattering of small pieces

83 (few 10-30 cm diameter pieces per $\mathrm{m}^{2}$ ). One piece of explosive material collected at the site was

84 analyzed and found to be composed of TNT, ammonium nitrate, aluminum powder, and Hexyl (2,4,6-

85 Trinitro-N-(2,4,6-trinitrophenyl)aniline $)^{30}$, while another was a combination of TNT, RDX, and Al powder

86 (likely a formulation known as Torpex) ${ }^{31}$. After numerous dives at the study site, explosive ordnance 
87 disposal (EOD) expert-trained research divers have noted that there are two visually distinct types of 88 exposed munition material present: one is grey-silver in color (likely similar to the reported Torpex), and 89 the other is orange-yellow in color (Fig. 1). The diversity of explosive sources at this study site (e.g., size 90 of exposed surface, explosive formulation, ageing, biofouling) is likely to contribute to variability in the

91 dissolution fluxes. It has unfortunately not been possible to further investigate the exact composition of

92 the residual material due to safety concerns and legal restrictions on transport and possession of

93 explosive material. Nonetheless, these exposed munition pieces provide a unique opportunity to study

94 processes affecting mobility and fate of $\mathrm{MC}$ in the marine environment.

95 Sample collection and in situ experiments took place during three research cruises on FK Littorina in 96 March, June, and October 2017 (denoted L17_03, L17_07, and L17_09, respectively). Water column 97 characteristics (e.g., temperature, salinity) were measured by CTD (Sea \& Sun Technology GmbH) to within approximately $2 \mathrm{~m}$ of the seafloor, but not deeper due to munition presence and safety concerns.

99 Manual syringe sample collection and benthic chamber deployment were conducted by EOD-trained 100 scientific divers from Christian-Albrechts-University, Kiel. These experiments were conducted as part of a 101 project developing environmental impact assessment strategies related to future robotic munition removal approaches (UDEMM: Environmental monitoring for the delaboration of munitions on the 103 seabed).
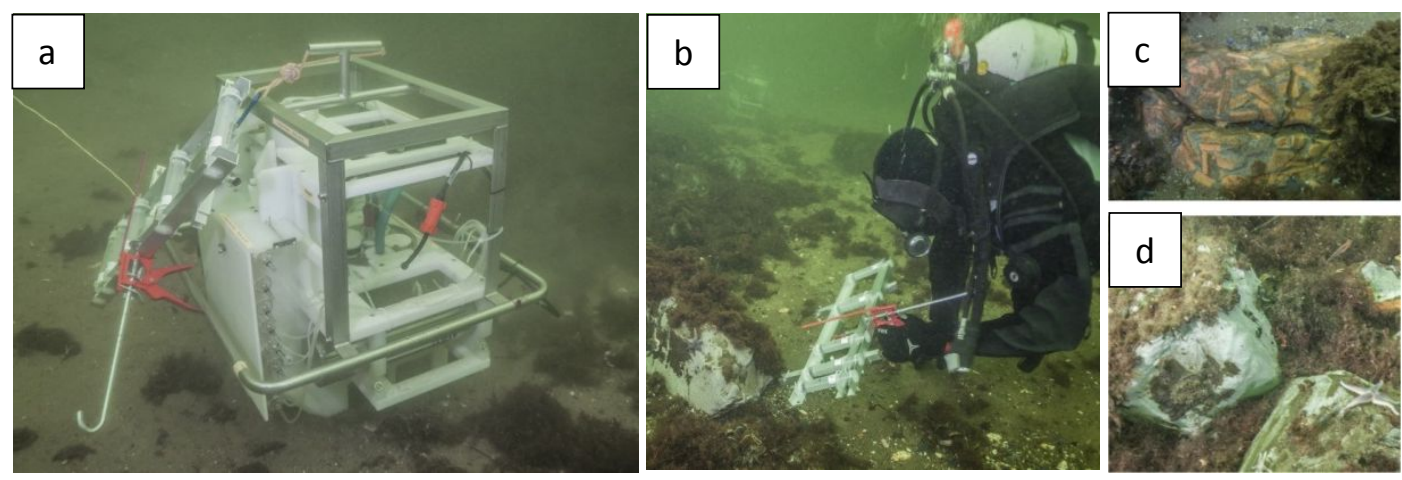
106 Figure 1. (a) Benthic chamber deployed on sandy bottom. The bank of glass syringes is visible on the left

107 side, connected via tubing to the chamber in the center. The manual syringe sampler hangs off the

108 handle to the left side. (b) Scientific diver preparing to collect a set of manual syringe samples adjacent

109 to an exposed block of grey-silver explosive material. (c) Orange-yellow colored munition piece. (d) Grey-

110 silver munition pieces. The scale in the latter two images is about 0.5 - $1 \mathrm{~m}$. (Images:

111 Forschungstauchzentrum CAU)

112 Syringe sampler (Gradient method)

113 The gradient method relies on samples collected manually by scientific divers at close intervals very near

114 and vertical to the exposed munition surface. Because bottom currents at the study site are weak and

115 variable (see Site Description), we assume that the direction of sampling did not greatly affect the

116 profiles. The first set of syringe samples was collected during the March cruise using four individual 60

$117 \mathrm{~mL}$ polypropylene syringes filled sequentially. We observed negligible adsorption of target analytes to

118 plastic sampling materials within the short holding time (Supporting Information). In order to facilitate

119 sampling and standardize the sampling distances during later sampling efforts, a device was custom-built

120 that allowed simultaneous filling of five syringes at fixed positions 5, 10, 20, 40, and $60 \mathrm{~cm}$ from the

121 munition surface (Fig. 1). Using this device, four sets of samples were collected during the June cruise,

122 and six sets of samples were collected during the October cruise. The sets were collected on separate

123 dives and on different munitions pieces. Most samples were collected near grey-silver pieces, but two

124 sets purposely targeted the orange-yellow fragments.

125 Benthic chambers

126 Benthic flux chambers ${ }^{32}$ (Fig. 1) were adapted in this study for measuring dissolution of solid munition

127 pieces by emplacement over exposed fragments of explosive material resting on the flat sandy seafloor.

128 Chambers were cylindrical polycarbonate enclosures $19 \mathrm{~cm}$ in diameter, and contained about $9 \mathrm{~L}$ of 
129 water after insertion $\sim 5 \mathrm{~cm}$ deep into the sediment. Water within the chamber was mixed very gently by

130 a small rotor in the chamber lid. After deployment and a delay period, the chamber was flushed with

131 ambient water for 30 minutes by an impeller pump. Samples were collected automatically at

132 predetermined intervals $(0.2-10 \mathrm{~h})$ with $60 \mathrm{~mL}$ glass syringes connected to the chamber by Vygon

133 tubing. Dissolved oxygen was monitored inside and outside the chamber by two optodes (ANDERAA) to

134 evaluate if sediment enclosure in the chambers affected redox conditions.

135 Two separate benthic chambers were deployed during both March and October cruises. In March, one 136 chamber failed to operate and the other collected samples only during the first 15 hours, but both

137 chambers worked for the entire 48h deployment in October (although data from one chamber could only

138 be used before the 25h time point, see below). During the March deployment (L17_03), the benthic 139 chamber was placed over an orange-yellow munition piece that was approximately $5 \times 6 \times 4 \mathrm{~cm}\left(118 \mathrm{~cm}^{2}\right.$, 140 not including the face lying on the sediment). In October (L17_09), both pieces were grey-silver colored 141 and approximately $6 \mathrm{~cm}$ on all sides $\left(180 \mathrm{~cm}^{2}\right)$.

\section{Chemical analysis}

143 After collection, water samples were transferred to $50 \mathrm{~mL}$ polypropylene centrifuge tubes, stored at $4{ }^{\circ} \mathrm{C}$,

144 and processed within $24 \mathrm{~h}$. Dissolved MC were measured by ultra high performance liquid

145 chromatography-electrospray ionization mass spectrometry (uHPLC-ESI-MS) ${ }^{33}$. Briefly, all samples were

146 initially diluted 100 -fold with 50\% LCMS-grade methanol and measured following direct injection.

147 Samples with concentrations below approximately $1 \mu \mathrm{g} \mathrm{L}^{-1}$ were preconcentrated on Chromabond Easy

148 resin columns, eluted with LCMS-grade acetonitrile, brought to near dryness, and reconstituted in $50 \%$

149 LCMS-grade methanol. Samples were then measured as for direct injection. Detection limits of this

150 method are on the order of $0.01 \mu \mathrm{g} \mathrm{L}^{-1}$ for the analytes of interest. 
152 Turbulent mixing drives water exchange near submerged explosive surfaces, and therefore is a dominant

153 control on mass transfer and dissolution. Eddy diffusion coefficients $\left(K_{v}\right)$ were estimated using two

154 independent approaches based on (1) calculation using velocity profiles in the water column, and (2)

155 eddy-diffusion values extracted from an eddy-resolving hydrodynamic model, the General Estuarine

156 Transport Model (GETM). Under normal conditions, the turbulence structure could be very highly

157 resolved using a Microstructure Probe, but it is unfortunately not possible to use a free-falling

158 instrument in a munitions-contaminated site due to explosion risk. An Acoustic Doppler Current Profiler

159 (ADCP) was deployed at the sea bed almost continuously throughout 2017. The ADCP recorded water

160 current velocity and direction every 15 minutes in bins of $25 \mathrm{~cm}$ height from $1.3 \mathrm{~m}$ above the bed up to

161 the water surface. Current velocity profiles were time-averaged (following ${ }^{34}$ ), and the resulting profile

162 used to estimate the eddy diffusion coefficient. Averages were calculated over the cruise sampling

163 periods in June and October, representing 208 and 128 individual profiles, respectively. For the March

164 cruise, velocity data was not available for the exact sampling date (16 March), hence the first available

165 date afterwards (30 March) was used (66 individual velocity profiles).

166 For this study, we used a western Baltic Sea configuration of the hydrodynamic model GETM with a

167 horizontal resolution of $1 / 3$ nautical mile (approx. $600 \mathrm{~m}$ ). The model domain covers the Danish Straits

168 and the western Baltic. The model setup uses realistic atmospheric forcing derived from the operational

169 model of the German Weather Service (DWD) with a spatial resolution of $7 \mathrm{~km}$ and temporal resolution

170 of $3 \mathrm{~h}$. In the vertical we used 42 terrain-following adaptive layers, with a minimum layer thickness of 0.3

$171 \mathrm{~m}$. The present setup is identical to the one used by ${ }^{35}$ and a detailed description and validation of the

172 used setup is given in ${ }^{36}$ and ${ }^{37}$. Results from the GETM model for 2017 were not available, so eddy

173 diffusion values were taken from the 2016 model run. Values were calculated every 30 minutes between

174 Jan 1 and Oct 31, for the vertical bin closest to the seafloor. Although both methods required

175 compromises in terms of data availability and timing, the objective here was to constrain a 
176 representative eddy diffusion value for the site. Fine scale variability in $K_{v}$ may exist within the site or

177 over short time scales, and this adds an additional degree of uncertainty to the dissolution flux

178 estimates.

\section{Results}

Water column profiles of salinity and temperature showed weak stratification approximately 4-5 m 183 above the seafloor, with a well-mixed layer above (Supporting information, Fig. S2). Water temperature

184 was lowest in March $\left(3.3-3.9^{\circ} \mathrm{C}\right)$, and salinity was highest $(16.1-18.2)$. In June, water temperature was highest $\left(15.4-16.5^{\circ} \mathrm{C}\right)$ and salinity intermediate $(16.7-17.5)$. In October, stratification was weakest, with intermediate salinity $(15.4-16.5 \mathrm{ppt})$ and the narrowest range in water temperature (13.5 $13.6^{\circ} \mathrm{C}$ ). Dissolved oxygen and $\mathrm{pH}$ (NBS scale) were only measured during the October cruise, and ranged between 240 and $320 \mu \mathrm{M}$, and 7.5 and 7.9, respectively. Bottom waters were around $85 \%$ oxygen saturation.

\section{Manual syringe samples}

Syringe samples were collected along a $50 \mathrm{~cm}$ long transect with individual syringes in March. Because

193 individual syringes were used, the first sample was collected directly at the munition surface (i.e., at $0 \mathrm{~cm}$ 194 from the solid surface). Dissolved TNT in this sample was $3100 \mu \mathrm{g} \mathrm{L}-1$ (Fig. 2), the highest observed in any 195 manual syringe sample. Concentrations declined rapidly away from the munition surface, to $16 \mu \mathrm{L} \mathrm{L}^{-1}$ at 1 $196 \mathrm{~cm}$ and finally $3.3 \mu \mathrm{g} \mathrm{L}^{-1}$ at $50 \mathrm{~cm}$ distance. Dissolved RDX and DNB showed a similar trend, but the concentrations were lower $\left(\sim 1-10 \mu \mathrm{g} \mathrm{L}^{-1}\right)$. Samples collected during the June and October cruises showed less striking decreases (maximum measured TNT was $50 \mu \mathrm{g} \mathrm{L}^{-1}$ ), likely because the simultaneous 
199 syringe sampling device collected the first sample at $5 \mathrm{~cm}$ distance from the munition surface. Indeed,

200 the trends and concentrations in March match the other sampling periods when distances $1 \mathrm{~cm}$ and

201 greater are considered. Most samples from these later cruises showed monotonous declines in TNT away

202 from the munition surface, although three sets did not show elevated levels in the near-surface sample

203 (distance $=5 \mathrm{~cm}$ ). The lowest concentrations were consistently observed for RDX, generally $1-2 \mu \mathrm{L} \mathrm{L}^{-1}$ or

204 less, and profiles often did not show a clear decreasing trend away from the surface. Trends were also

205 less clear for DNB, although concentrations were as high $22 \mu \mathrm{g} \mathrm{L}^{-1}$.

206 Most syringe sample sets were collected near grey-silver colored munition pieces, although two sets

207 collected in October intentionally targeted the orange-yellow colored pieces. Trends for TNT in these

208 sample sets were not markedly different from those collected on the grey-silver pieces, with

209 concentrations nearest the surface of $22-23 \mu \mathrm{g} \mathrm{L}^{-1}$. No obvious difference was apparent for RDX or TNB

210 either; highest measured concentrations of DNB were measured in the samples from the orange-yellow

211 pieces, but the data were scattered and not substantially different from the other sample sets.

212 Benthic chambers

213 Benthic chambers were deployed twice, once in March (Chamber 1), and once in October (Chamber 2

214 and 3). Oxygen levels in the chambers declined slightly during the incubation, by between 15 and $25 \%$, to

$215291 \mu \mathrm{M}$ in March and $238 \mu \mathrm{M}$ in October (data not shown). The oxygen levels measured within

216 chambers in October were only slightly lower at the end of the incubation period than in the water

217 column, indicating that redox conditions within the chambers were not greatly altered during the

218 incubation.

219 During the March cruise, one chamber failed to operate, and the second stopped collecting samples after 22015 hours. Nonetheless, the retrieved samples showed an increase in concentration within the chamber

221 ("Chamber 1", Fig. 3). During this deployment, the chamber was placed over an orange-yellow munition 
222 piece. Very little TNT dissolution was observed in this chamber (maximum $58 \mu \mathrm{g} \mathrm{L} \mathrm{L}^{-1}$, after $15 \mathrm{~h}$ ), although 223 RDX concentrations reached $920 \mu \mathrm{g} \mathrm{L}^{-1}$ after $15 \mathrm{~h}$. In contrast, DNB reached levels of $11300 \mu \mathrm{g} \mathrm{L}^{-1}$. The 224 temporal trend was similar for RDX and DNB.

225 In October, two chambers were deployed successfully (Fig. 3). In Chamber 2, dissolved TNT and DNB 226 increased monotonously, reaching concentrations of 4500 and $17.8 \mu \mathrm{g} \mathrm{L}^{-1}$, respectively. RDX increased 227 very slightly to less than $1 \mu \mathrm{g} \mathrm{L}-1$ over the $48 \mathrm{~h}$ incubation period. In Chamber 3, TNT and DNB increased 228 over the first five time points to 3410 and $46.2 \mu \mathrm{g} \mathrm{L}^{-1}$, respectively. RDX was not detected in the chamber 229 over this period. Between 15 and $25 \mathrm{~h}$, concentrations of TNT and DNB decreased to ambient levels $(<1$ $\left.230 \mu \mathrm{g} \mathrm{L}^{-1}\right)$. This was most likely caused by the chamber tilting and allowing ambient water to enter under the 231 chamber lip. Oxygen data in the chamber confirm this, with a slow decline in dissolved oxygen initially 232 that returned to ambient conditions and matched oxygen trends outside the chamber thereafter (data 233 not shown). Because of the sandy sediments in the study region, divers were unable to insert the 234 chamber mouth very deep, making them rather physically unstable. Regardless, the initial time points 235 appear to have provided reliable data. 

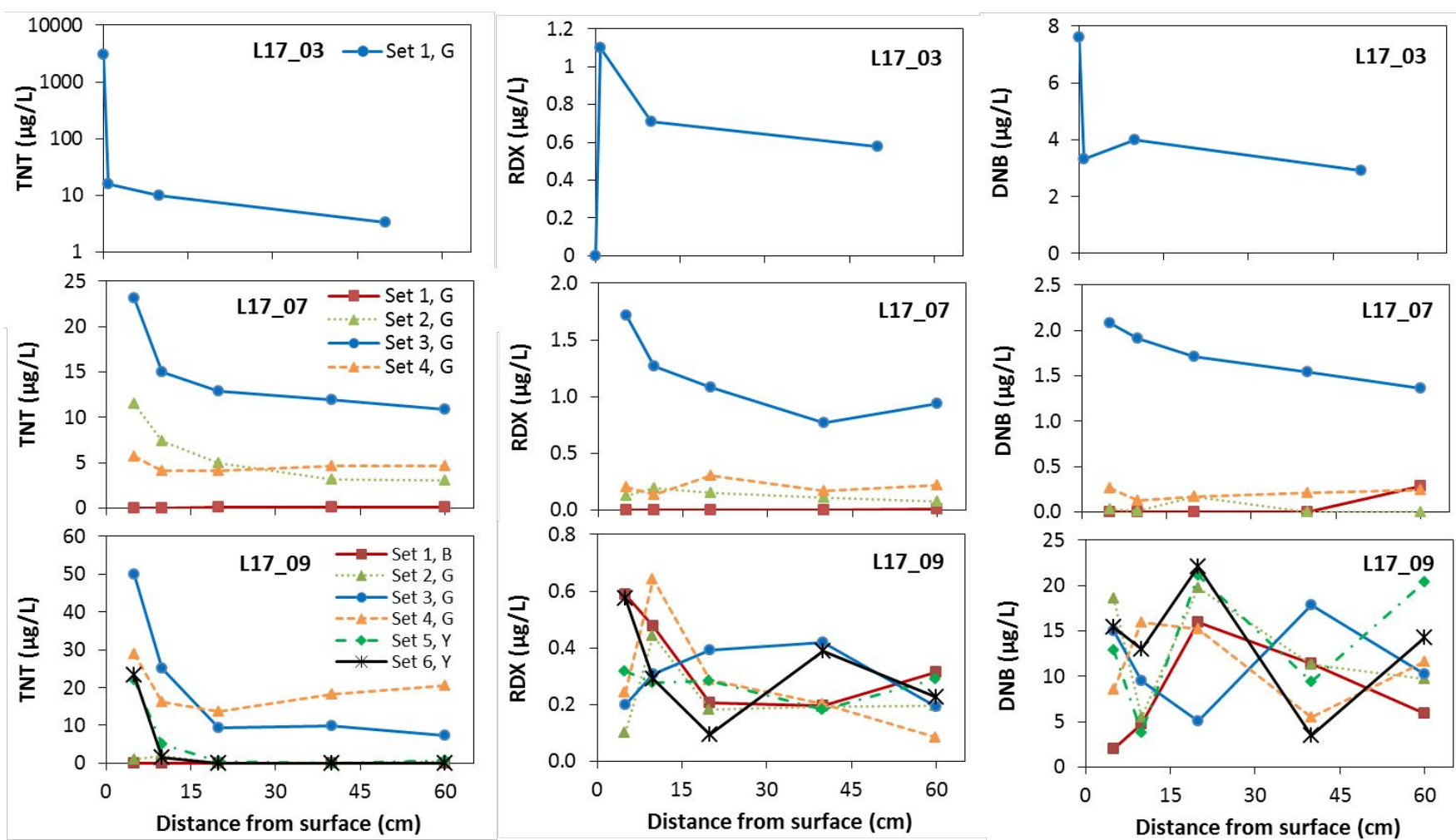

237 Figure 2. Manual syringe sample sets during three sampling cruises. L17_03: March 2017, L17_07: June 2017, L17_09: October 2017. Each set of

238 syringe samples was collected on a different exposed munition piece; letters indicate type: "G" is grey/silver colored, " $\mathrm{Y}$ " is orange-yellow colored,

239 and "B" is unknown. Note the log scale concentrations for L17_03 TNT. Replicate samples could not be obtained with the sampling device, and

240 uncertainties associated with the $\sim 5 \%$ analytical precision are omitted for clarity. 

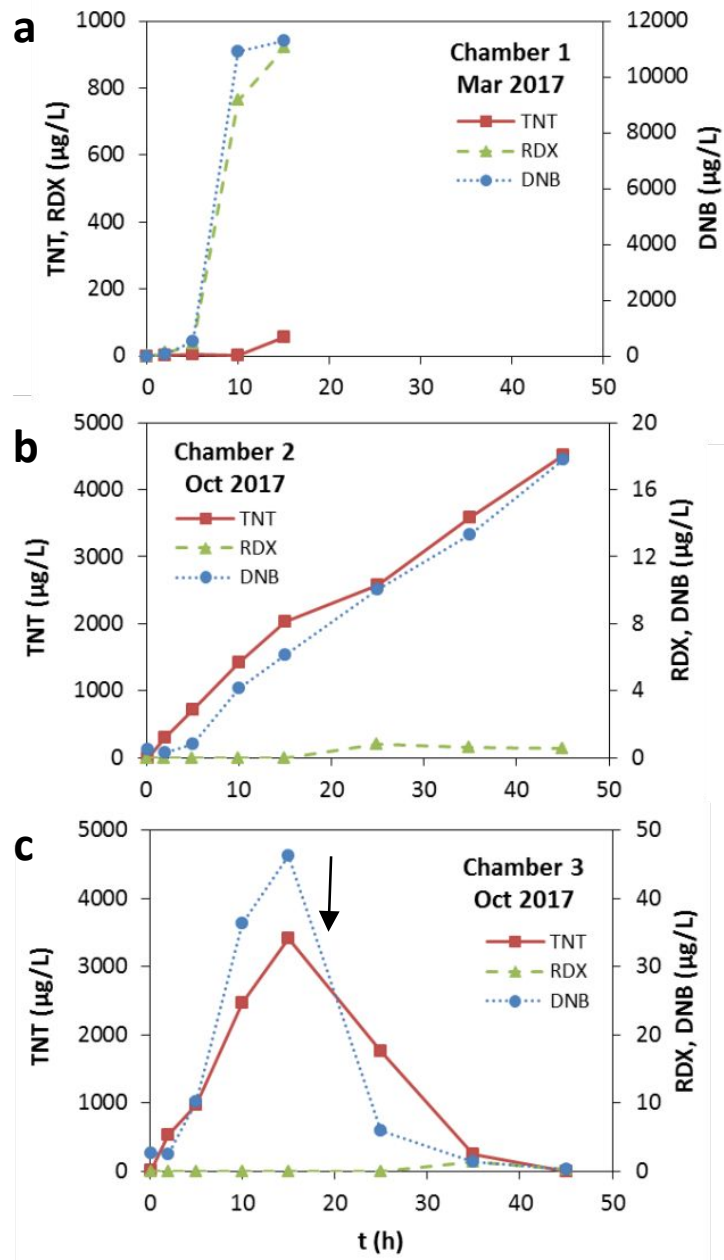

242

243 Figure 3. Time series of MC concentrations measured in benthic chambers (18 L volume). a) March 2017.

244 Syringe sampler failed mid-deployment, limiting the incubation time. b) October 2017, ideal deployment.

245 c) October 2017, replicate chamber. Concentrations declined between 15 and 25h (black arrow), likely

246 due to the chamber tilting and venting to surrounding water. Chamber 1 was placed over a yellow-

247 orange munition piece, whereas Chambers 2 and 3 were placed over grey-silver pieces. Replicate

248 samples could not be obtained with the sampling device, and uncertainties associated with the $~ 5 \%$

249 analytical precision are omitted for clarity. 
252 The velocity profiles generally adhered to the "law-of-the-wall" distribution ${ }^{38}$-i.e., exhibiting a

253 logarithmic profile close to the seabed "wall" (Fig. S3). The mean velocity, U(z), can therefore be

254 described as a function of depth according to:

$255 \quad U(z)=\left(\frac{u_{*}}{k}\right) \ln \left(\frac{z}{z_{0}}\right)$

Equation 1

256 where $u_{*}$ is the friction velocity, $k$ is the dimensionless von Kármán constant with a value of $0.41, z$ is the

257 height above the sea bed, and $z_{0}$ is the bottom roughness height. For each of the data periods, a mean

258 velocity profile was calculated from the measured profiles (Fig. S3). In a plot of $U(z)$ against $\ln (z), u_{*}$ is the

259 slope of the straight line fit for the bottom region multiplied by $k$. The height above the bed at which the

260 velocity is zero and the logarithmic profile starts $\left(z_{0}\right)$, can be calculated from this fit as well at the point $z$

$261=1$, i.e., $\ln (z)=0$, by re-arranging Eq. 1 to:

$Z_{0}=e^{U_{z=1}^{k} / u_{*}}$

Equation 2

263 In this case, the deepest 15 bins were used, corresponding to bin mid-depths from 1.3 to 4.8 meters

264 above the sea bed. During the sampling periods, $u *$ was estimated as $6.4 \pm 0.5 \mathrm{~mm} \mathrm{~s}^{-1}$ (June), $6.0 \pm 0.6 \mathrm{~mm}$

$265 \mathrm{~s}^{-1}$ (March), and $1.3 \pm 0.8 \mathrm{~mm} \mathrm{~s}^{-1}$ (October), with a $\mathrm{z}_{0}$ average of $6.6 \mathrm{~cm}$.

267 With $u_{*}$, we can calculate the near-bottom vertical eddy diffusion coefficient, $K_{v}$, which is given by ${ }^{38}$ :

$268 K_{v}=k u_{*} Z$ Equation 3

269 Accordingly, the value of $K_{v}$ increases linearly with height from $0 \mathrm{~m}^{2} \mathrm{~s}^{-1}$ at the sea bed. At a $10 \mathrm{~cm}$

270 sampling depth for the syringe profiles, the mean $K_{v}$ was $(2.5 \pm 0.2) \times 10^{-4},(2.6 \pm 0.2) \times 10^{-4}$, and $(0.5 \pm 0.3) \times 10^{-}$

$271{ }^{4} \mathrm{~m}^{2} \mathrm{~s}^{-1}$, for March, June, and October, respectively. Uncertainty on these $K_{v}$ values is propagated from

272 the error of the linear regression used to estimate $u_{*}$. 
274 As an independent approach for estimating the eddy diffusion coefficients (to improve confidence in the 275 dissolution rate calculations), values were also taken from the GETM circulation model. In general, 276 bottom water eddy diffusivities were higher during the stormier winter months, but there is a high 277 degree of variability over the period January to November 2016 (Fig. S4). Model results were not 278 available for 2017, so results for 2016 were substituted. Average values for March, June, and October 279 were $(0.8 \pm 2.1) \times 10^{-4},(0.2 \pm 0.7) \times 10^{-4}$, and $(0.6 \pm 10) \times 10^{-4} \mathrm{~m}^{2} \mathrm{~s}^{-1}$. Thus, model-derived values of $K_{v}$ are more 280 variable than the velocity profile approach, but match within the uncertainty.

281 The average eddy diffusivity of these two approaches across the sampling periods is $(1.2 \pm 1.1) \times 10^{-4} \mathrm{~m}^{2} \mathrm{~s}$

$282{ }^{1}$ (avg. \pm 1 s.d.), consistent with previous work showing order-of-magnitude increases in the average eddy 283 diffusivity in the Baltic Sea from interior basins $\left(\sim 10^{-6} \mathrm{~m}^{2} \mathrm{~s}^{-1}\right)$, to entire basin $\left(\sim 10^{-5} \mathrm{~m}^{2} \mathrm{~s}^{-1}\right)$, to basin margins 284 39. For the purpose of the current work, we use the average value of $1.2 \times 10^{-4} \mathrm{~m}^{2} \mathrm{~s}^{-1}$, although estimated 285 dissolution fluxes would change correspondingly if the actual diffusivities were higher or lower. Further 286 measurements with microstructure profilers, and sampling of MC gradients with higher temporal 287 resolution would be required to determine how well assumptions of steady state are met in this system.

\section{Discussion}

Dissolution fluxes by the gradient method

290 The syringe sample datasets generally showed elevated levels near the munitions surface, with a decline 291 towards the overlying water column. This trend suggests that MC are released to the water column by 292 dissolution of the solids, and mixing processes rapidly dilute the concentrations within $60 \mathrm{~cm}$ of the 293 munition surface. This is consistent with MC gradients observed by Rosen and colleagues ${ }^{40}$ in an 294 experiment using passive samplers and an explosive point source. Degradation is unlikely to contribute 
295 to the decrease given that MC half-lives in the marine environment are on the order of days to weeks $\left({ }^{41}\right.$, 296 and references therein).

297 A simple steady state model can be devised under which the dissolution rate at the munition surface $298\left(J_{\text {dissol }}\right)$ is equal to the flux of dissolved MC from the solid material $\left(J_{M C}\right)$ controlled by eddy diffusion. The 299 flux is proportional to the product of the eddy diffusion coefficient $\left(K_{v}\right)$, the area normal to the source, 300 and the concentration gradient away from the surface ${ }^{42}$. For radial diffusion from an explosive piece on 301 the seafloor, the area normal to the source at distance $r$ from the center of the half sphere is $2 \pi r^{2}, S A$ is 302 the explosive surface area, and the MC concentration gradient is $d C_{M C} d r$ :

$303 \quad J_{\text {dissol }}=J_{M C}=-K_{v}\left(\frac{2 \pi r^{2}}{S A}\right) \frac{d C_{M C}}{d r}$ Equation 4

304 The eddy diffusion coefficient is estimated using the velocity profiles and GETM model results, and the 305 concentration gradient is calculated from the two samples in each syringe set closest to the munition 306 surface $(r=10 \mathrm{~cm}$; Table 1$)$. For the sample set from cruise L17_03, the concentration gradient was 307 estimated using samples at 1 and $10 \mathrm{~cm}$ (omitting the high concentration measured directly at the 308 explosive surface). Turbulent diffusion decreases rapidly near to the solid surface, so the first sample 309 therefore overestimates the concentration gradient corresponding to the applied eddy diffusion 310 coefficient, and gives a flux estimate that is unrealistically high. To make this first sample set consistent 311 with the others, only data from distances $>1 \mathrm{~cm}$ were used to estimate the gradient.

312 The point source is assumed to have a surface area of $100 \mathrm{~cm}^{2}$, similar to the explosive pieces used in 313 benthic chamber deployments (below), although many explosive pieces at the site are larger (e.g., Fig. 1).

314 As the area of the exposed surface increases, the source becomes more laterally uniform, and a 1-

315 dimensional model is more appropriate (i.e., eliminating the $2 \pi r^{2} / S A$ term from Eq. 4 , and decreasing the 316 flux estimate). Thus, the fluxes estimated here probably represent the maximum values for this site. 
317 Dissolution fluxes estimated using this approach were consistent among the different sample sets (Table 318 1). For TNT and DNB, dissolution fluxes were generally on the order of $10^{-1}-10^{0} \mathrm{mg} \mathrm{cm}^{-2} \mathrm{~d}^{-1}$, and RDX 319 dissolution on the order of $10^{-2}-10^{-1} \mathrm{mg} \mathrm{cm}^{-2} \mathrm{~d}^{-1}$. 
Table 1. Dissolved MC gradients near munitions surfaces, and calculated dissolution fluxes (where $K_{v}=1.2 \times 10^{-4} \mathrm{~m}^{2} \mathrm{~s}^{-1}$ ). Letters in the sample ID refer to the apparent munition type, as described in the Methods section: "G" is grey-silver, " $Y$ " is orange-yellow, and " $B$ " is unknown.

\begin{tabular}{|c|c|c|c|c|c|c|c|}
\hline & & \multicolumn{3}{|c|}{$\mathrm{dC} / \mathrm{dr}\left(\mathrm{ng} \mathrm{cm}^{-3} \mathrm{~cm}^{-1}\right)$} & \multicolumn{3}{|c|}{$J_{\text {dissol }}\left(\mathrm{mg} \mathrm{cm}^{-2} \mathrm{~d}^{-1}\right)$} \\
\hline & & TNT & RDX & DNB & TNT & RDX & DNB \\
\hline L17_03* & Set $1, G$ & 0.67 & 0.043 & -- & 0.4 & 0.03 & -- \\
\hline \multirow[t]{4}{*}{ L17_07 } & Set $1, \mathrm{G}$ & 0.002 & 0.0001 & -- & 0.001 & 0.0001 & -- \\
\hline & Set $2, \mathrm{G}$ & 0.83 & -- & 0.005 & 0.5 & -- & 0.003 \\
\hline & Set $3, \mathrm{G}$ & 1.6 & 0.090 & 0.036 & 1.1 & 0.1 & 0.02 \\
\hline & Set $4, \mathrm{G}$ & 0.32 & 0.013 & 0.027 & 0.2 & 0.01 & 0.02 \\
\hline \multirow[t]{6}{*}{ L17_09 } & Set $1, B$ & 0 & 0.022 & -- & 0 & 0.01 & -- \\
\hline & Set $2, \mathrm{G}$ & -- & -- & 2.6 & -- & -- & 1.7 \\
\hline & Set $3, \mathrm{G}$ & 4.9 & -- & 1.1 & 3.2 & -- & 0.7 \\
\hline & Set $4, \mathrm{G}$ & 2.5 & -- & -- & 1.6 & -- & -- \\
\hline & Set $5, Y$ & 3.4 & 0.008 & 1.8 & 2.2 & 0.01 & 1.2 \\
\hline & Set $6, Y$ & 4.4 & 0.057 & 0.47 & 2.8 & 0.04 & 0.3 \\
\hline Average & & $1.9 \pm 1.8$ & $0.033 \pm 0.032$ & $0.87 \pm 1.0$ & $1.2 \pm 1.2$ & $0.022 \pm 0.021$ & $0.57 \pm 0.67$ \\
\hline
\end{tabular}

*For L17_03, the concentration gradient is estimated using samples

between 1 and $10 \mathrm{~cm}$ distance (see text).

Estimates are omitted where gradients increase away from the munition

surface.

Uncertainties on individual estimates are not available because each sample

profile represents a single set of unreplicated samples. The standard

deviation of the average gives the best indication of uncertainty on these

estimates. 
322 Dissolution fluxes were calculated in benthic chamber experiments by fitting linear regression trendlines

323 (intercept at the origin) to the incubation data, giving the rate, $R\left(\mu \mathrm{L} \mathrm{L}^{-1} \mathrm{~d}^{-1}\right)$, of concentration increase as

324 a function of time. Fluxes were then calculated using the exposed surface area of the enclosed munition 325 pieces $\left(A ; \mathrm{cm}^{2}\right)$, and the volume of the chamber $(\mathrm{V} ; \mathrm{L})$ :

$326 \quad J_{\text {chamber }}=\frac{R \times V}{A}$

Equation 5

327 All data were used in Chambers 1 and 2; in Chamber 3, only data from the first 15 hours were considered 328 (Table 2). A striking difference in MC dissolution was observed between the orange-yellow munition 329 piece (Chamber 1) and the grey-silver pieces (Chambers 2 and 3) (Fig. 3). Concentrations of DNB and RDX 330 increased greatly in Chamber 1, suggesting that these two compounds make up a major portion of the 331 orange-yellow munition solids. Dissolution fluxes of DNB and RDX in Chamber 1 were similar to the 332 gradient samples. In contrast, TNT dissolution in Chamber 1 was slower than any of the estimates made 333 by the gradient method. Given the apparent DNB/RDX composition of the orange-yellow solids, it is 334 surprising that neither of these compounds were visibly elevated in syringe samples collected near 335 orange-yellow pieces (Fig. 2). This is probably either because the chemical composition is in fact not 336 related to the color, or there is substantial heterogeneity in the chemical emission from the solids and 337 syringe sampling inadvertently missed the plume.

338 Table 2. Dissolution fluxes obtained from benthic chamber incubations.

\begin{tabular}{cccc}
\hline & \multicolumn{3}{c}{ Dissolution rate $\left(\mathrm{mg} \mathrm{cm}^{-2} \mathbf{~ d}^{-1}\right)$} \\
\cline { 2 - 4 } & TNT & RDX & DNB \\
\hline \hline Chamber 1 $^{\text {a }}$ & $(4.7 \pm 1.6) \times 10^{-3}$ & $0.11 \pm 0.016$ & $1.45 \pm 0.24$ \\
Chamber 2 $^{\text {a }}$ & $0.125 \pm 0.005$ & $(1.8 \pm 0.4) \times 10^{-5}$ & $(4.7 \pm 0.1) \times 10^{-4}$ \\
Chamber 3 $^{\mathrm{b}}$ & $0.277 \pm 0.008$ & 0 & $(3.8 \pm 0.3) \times 10^{-3}$ \\
\hline
\end{tabular}

a Calculated using all data

b Calculated using data from 0-15 h 
Uncertainties are calculated from the error on the regression used to derive the rate of concentration increase in the chambers with time $(R$, Eq. 5)

340 In Chambers 2 and 3, little RDX dissolution was evident, but both TNT and DNB showed substantial

341 dissolution (Fig. 3). The increasing concentration trend was identical for TNT and DNB in both chambers,

342 but TNT reached levels that were approximately 100-fold higher than DNB. Dissolved TNT concentrations

343 in the chambers reached approximately $4 \mathrm{mg} \mathrm{L}^{-1}$, which is about 5-10\% of the saturation limit ( $50-80 \mathrm{mg}$

$344 \quad \mathrm{~L}^{-1}$ at $3-15^{\circ} \mathrm{C}$; see compilation in $\left.{ }^{41}\right)$. This is consistent with previous studies showing very high

345 concentrations of $\mathrm{MC}$ within cavities of breached munitions ${ }^{12}$, and suggests a high level of heterogeneity

346 in MC concentration within munitions-contaminated sites, depending on frequency and intensity of

347 water exchange.

348 Dissolution fluxes for TNT, RDX, and DNB in the benthic chambers were between approximately $10^{-4}$ and $34910^{-1} \mathrm{mg} \mathrm{cm}^{-2} \mathrm{~d}^{-1}$ (Table2). Chamber fluxes matched well with those estimated from the gradient samples 350 for TNT in Chambers 2 and 3, whereas RDX and DNB fluxes in Chamber 1 matched the gradient-method 351 estimates better. Little RDX and DNB dissolution was observed in Chambers 2 and 3, and estimated 352 fluxes were several orders of magnitude lower than estimated from the syringe sample gradients. These 353 differences most likely reflect the high degree of variability in the munitions present in marine 354 dumpsites. There are many formulations with different nominal compositions (e.g., Filling 84: 100\% DNB 355 vs. Filling 96: 50\% each TNT and RDX); there are more than 430 different German explosive mixtures ${ }^{43}$, 356 and actual formulations likely varied from the nominal composition during wartime due to ingredient 357 availability. 
Table 3. Comparison of dissolution fluxes measured in the current work with those reported from previous studies in fresh and brackish water.

\begin{tabular}{|c|c|c|c|c|c|c|}
\hline \multirow[b]{2}{*}{ Solvent } & \multirow{2}{*}{$\begin{array}{l}\text { Explosive } \\
\text { formulation }\end{array}$} & \multicolumn{3}{|c|}{ Dissolution rate $\left(\mathrm{mg} \mathrm{cm}^{-2} \mathrm{~d}^{-1}\right)$} & \multirow[b]{2}{*}{ Notes } & \multirow[b]{2}{*}{ Reference } \\
\hline & & TNT & RDX & DNB & & \\
\hline Seawater (15-18 ppt) & Unknown & $0.0047-0.277$ & $0.000018-0.11$ & $0.00047-1.45$ & Benthic chamber incubation & This work \\
\hline Distilled water & Octol & 0.072 & n.m. & n.a. & $25^{\circ} \mathrm{C}$, no stirring. & 21 \\
\hline Rainwater & Comp B & 0.329 & 0.324 & n.a. & Column experiment, $10 \mathrm{~cm} / \mathrm{d}$ flow & 44 \\
\hline Rainwater & $\mathrm{C} 4$ & n.a. & 0.674 & n.a. & Column experiment, $10 \mathrm{~cm} / \mathrm{d}$ flow & 44 \\
\hline Seawater (15-18 ppt) & Unknown & $0.001-3.2$ & $0.0001-0.04$ & $0.003-1.7$ & Open water gradient method & This work \\
\hline Deionized water & Comp B & 5.6 & 1.7 & n.a. & Stirred, $150 \mathrm{rpm}$ & 17 \\
\hline Sea water (20 ppt) & Comp B & 5.6 & 1.9 & n.a. & Stirred, 150 rpm & 17 \\
\hline Deionized water & Octol & 11 & n.m. & n.a. & Stirred, $150 \mathrm{rpm}$ & 17 \\
\hline Sea water (20 ppt) & Octol & 10 & n.m. & n.a. & Stirred, $150 \mathrm{rpm}$ & 17 \\
\hline Sea water (20 ppt) & Pure solid & 13 & n.m. & n.a. & Stirred, $150 \mathrm{rpm}$ & 17 \\
\hline Deionized water & Octol, GIM & $12-28$ & n.m. & n.a. & Stirred, $300 \mathrm{rpm}$ & 19 \\
\hline Deionized water & Pure solid & 18 & n.m. & n.a. & Stirred, 150 rpm & 17 \\
\hline Deionized water & Pure solid & $70-76$ & $1.2-8.4$ & n.a. & Stirred, $90-210 \mathrm{rpm}, 10-30^{\circ} \mathrm{C}$ & 15,45 \\
\hline Deionized water & Comp B & 74 & 40 & n.a. & Shaker table at $225 \mathrm{rpm}$ & 46 \\
\hline Unknown & Unknown & 100 & 8.64 & n.a. & "Completely stirred" & 25 \\
\hline
\end{tabular}

n.a. - Not Applicable

n.m. - Not Measured 
361 The dissolution fluxes determined in the current work show large variability, but are similar to the lower

362 laboratory measurements reported in the literature (Table 3). Dissolution fluxes measured with the

363 benthic chambers match the lowest reported fluxes for TNT and RDX. The gradient method estimates are

364 similar to the lowest reported fluxes for TNT, whereas estimates for RDX are lower than literature values

365 by 100 -fold or more. We are not aware of any previous measurements of DNB dissolution fluxes, but the

366 estimates here are similar to TNT and RDX.

367 There is large variability in the dissolution rates estimated in the current study, but they are nonetheless

368 lower by orders-of-magnitude than most of the rates reported in the literature. It is possible that the

369 eddy diffusion coefficients applied here were too low (note, for example, the GETM model estimates in

370 Fig. S4 show large variability around the mean), which would underestimate the true flux. In addition, we

371 were unable to measure the exact composition of the dissolving source material, so it remains unknown

372 how well the aged explosive material present in Kolberger Heide can be compared with formulations

373 used in previous laboratory experiments.

374 We believe instead that the difference between our in situ rates and those from previous laboratory

375 studies results from the degree of stirring or mixing during the experiment. The benthic chamber results

376 match best with column experiments with very slow flow ${ }^{44}$ or batch experiments with no stirring ${ }^{21}$. The

377 gradient method estimates match better with experiments under slightly higher stirring speeds,

378 suggesting control by rapid water mixing in shallow coastal waters. Dissolution fluxes estimated with the

379 gradient method were similar for different sampling cruises, suggesting that temperature differences

380 had little effect on dissolution, despite variations of $3-16^{\circ} \mathrm{C}$. Estimates in the current study are similar to

381 literature values for both fresh and higher salinity water, suggesting that a salinity effect on dissolution is

382 likely small relative to other factors. It is therefore likely that dissolution of exposed munitions on the 
seafloor and release of MC to the water column is limited in low-energy marine systems, such as deep waters. However, in shallow coastal systems, tides, wind, and waves may greatly enhance water mixing around objects on the seafloor, and increase the rate of $\mathrm{MC}$ release from underwater munitions. Storm events may also lead to episodic pulses of MC release.

From the MC fluxes estimated in the current work (1-3 $\mathrm{mg} \mathrm{cm}^{-2} \mathrm{~d}^{-1}$, at the high end), and assuming a munition material density ${ }^{47}$ on the order of $2 \mathrm{~g} \mathrm{~cm}^{-3}$, we can estimate that the surface of exposed underwater munitions will retreat at a rate on the order of $1-5 \mathrm{~mm} \mathrm{y}^{-1}$. This low value is consistent with observations in a study in Sweden where artillery shells were purposely cleaved and incubated in situ for three years, but very little dissolution was discernible by visual inspection ${ }^{11}$. This also explains why exposed munition material that was likely generated by low-order (i.e., incomplete) detonations in $2009^{28}$ is still abundant at the Kolberger Heide study site. Indeed, 70 years have elapsed since most marine munitions were dumped following World War II, corresponding at the low range of our estimates to only about $13 \mathrm{~cm}$ of linear dissolution for munition material that was not enclosed in metal housings.

One striking result of the current study is the observation that solid munition material at this one study site appears to have a highly variable composition. There is a vast array of explosives formulations ${ }^{43}$, and dumping activities likely included a variety of explosives types. As previous studies have noted, explosive formulation can affect dissolution behavior, with suppression of more soluble compounds such as TNT by less soluble components such as $\mathrm{HMX}^{16,18-20}$. Furthermore, explosive mixtures make underwater munitions point sources of a cocktail of different $\mathrm{MC}$, and potential toxicological effects on associated ecosystems should be evaluated in the context of exposure to multiple toxicants.

404 The total release of toxic MC from underwater munitions depends on dissolution flux and the exposed surface area of explosive material, and this surface area is a critical factor for assessing risk of ecological exposure to MC. The total flux of MC to the water column depends on the exposed surface area, not the 
407 number of munitions or area of the dump site. Constraining the area of exposed explosive surface is

408 likely to be very difficult, especially given the first-order challenge of classifying munition-like objects on

409 the seafloor ${ }^{48}$. Concentrations of dissolved MC in the water column may provide a more direct indication

410 of the $\mathrm{MC}$ release rate, although loss by processes such as mixing, degradation/transformation, and

411 sorption complicate the direct relationship. The variable but low dissolution fluxes estimated in the

412 current work suggest that modeling of $\mathrm{MC}$ release and spread from underwater munitions would benefit

413 from better constraint of the dissolution rate parameter, particularly under different mixing conditions.

414 Solid explosives likely dissolve more rapidly in settings with high mixing rates, but may persist on the

415 seafloor longer than expected under quiescent conditions. Where water mixing rates are low,

416 concentrations of dissolved MC at the solid surface or within breached munitions can increase to levels

417 that approach solubility limits. Given that underwater munitions can effectively act as bottom structure

418 and habitat ${ }^{9,10}$, marine organisms around the munitions may be exposed to concentrations many orders

419 of magnitude higher than present in the bulk water column.

\section{Acknowledgements}

421 We greatly appreciate the enthusiastic sampling assistance from the Forschungstauchzentrum (Christian-

422 Albrechts-Universität, Kiel) and the captain and crew of F/K Littorina. We also thank S. Sommer

423 (GEOMAR) for his generous loan of the benthic chambers, and S. Cherednichenko for his instruction on

424 their use. EMvdL wishes to thank Dr. Lars Umlauf for his idea of, and help with, using the law-of-the-wall.

425 Two anonymous reviewers provided thoughtful and constructive comments that improved the

426 manuscript. This work was funded by the German Federal Ministry of Education and Research (BMBF)

427 through the project UDEMM (Umweltmonitoring für die DElaboration von Munition im Meer, Project

428 number 03F0747, subprojects AkViCheMM and HyMeSiMM), and GEOMAR Helmholtz Centre for Ocean

429 Research. 
430 Supporting Information Available. Additional information on German-language references. Fig S1. Study

431 site. Fig. S2. Water column profiles. Fig. S3. ADCP velocity profiles. Figure S4. Eddy diffusion coefficients

432 calculated using the GETM model. Brief description of analyte sorption loss tests.

433 This information is available free of charge via the Internet at http://pubs.acs.org. 


\section{References}

435 1. Carton, G. \& Jagusiewicz, A. Historic Disposal of Munitions in U.S. and European Coastal Waters, 436 How Historic Information Can be Used in Characterizing and Managing Risk. Mar. Technol. Soc. J.

$437 \quad 43,16-32(2011)$.

438 2. Monfils, R., Gilbert, T. \& Nawadra, S. Sunken WWII shipwrecks of the Pacific and East Asia: The 439 need for regional collaboration to address the potential marine pollution threat. Ocean Coast. $440 \quad$ Manag. 49, 779-788 (2006).

441 3. Aker, J., Howard, B. \& Reid, M. Risk Management For Unexploded Ordinance (UXO) In The Marine 442 Environment. Dalhousie J. Interdiscip. Manag. 8, 1-22 (2012).

443 4. Edwards, R. Danger from the deep. New Sci. 148, 16-17 (1995).

444 5. Bohne, J. WWII bombs explode at North Sea wind farm. Dtsch. Welle (2012). at $445 \quad<$ http://www.dw.de/wwii-bombs-explode-at-north-sea-wind-farm/a-16360735>

446 6. Sanderson, H. \& Fauser, P. Environmental Assessments Of Sea Dumped Chemical Warfare Agents: 447 CWA report. Sci. Rep. from DCE - Danish Cent. Environ. Energy 174, 1-116 (2015).

$4487 . \quad$ Tornero, V. \& Hanke, G. Identification of marine chemical contaminants released from sea-based 449 sources: A review focusing on regulatory aspects. Eur. Comm. Jt. Res. Cent. JRC102452, 1-130

450 (2016).

451 8. Lotufo, G. R., Chappell, M. A., Price, C. L., Ballentine, M. L., Fuentes, A. A., Bridges, T. D., George, 452 R. D. \& Glisch, E. Review and synthesis of evidence regarding environmental risks posed by 453 munitions constituents (MC) in aquatic systems. ERDC/EL TR-17-17. 1-254 (2017).

454 9. Della Torre, C., Petochi, T., Corsi, I., Dinardo, M. M., Baroni, D., Alcaro, L., Focardi, S., Tursi, A., 
455

456

457

458

459

460

461

462
Marino, G., Frigeri, A. \& Amato, E. DNA damage, severe organ lesions and high muscle levels of As and $\mathrm{Hg}$ in two benthic fish species from a chemical warfare agent dumping site in the Mediterranean Sea. Sci. Total Environ. 408, 2136-2145 (2010).

10. McDonald, J. Demonstration of the Marine Towed Array on Bahia Salinas del Sur Vieques, Puerto Rico. ESTCP Rep. MM-0324. 1-133 (2009).

11. Ek, H., Dave, G., Nilsson, E., Sturve, J. \& Birgersson, G. Fate and effects of 2,4,6-trinitrotoluene (TNT) from dumped ammunition in a field study with fish and invertebrates. Arch. Environ. Contam. Toxicol. 51, 244-252 (2006).

12. Porter, J. W., Barton, J. V. \& Torres, C. Ecological, Radiological, and Toxicological Effects of Naval Bombardment on the Coral Reefs of Isla de Vieques, Puerto Rico. Warf. Ecol. A New Synth. Peace Secur. 65-122 (2011). doi:10.1007/978-94-007-1214-0

13. Koide, S., Silva, J. A. K., Dupra, V. \& Edwards, M. Bioaccumulation of chemical warfare agents, energetic materials, and metals in deep-sea shrimp from discarded military munitions sites off Pearl Harbor. Deep. Res. Part II Top. Stud. Oceanogr. 128, 53-62 (2016).

14. Strehse, J. S., Appel, D., Geist, C., Martin, H. J. \& Maser, E. Biomonitoring of 2,4,6-trinitrotoluene and degradation products in the marine environment with transplanted blue mussels (M. edulis). Toxicology 390, 117-123 (2017).

15. Lynch, J. C., Brannon, J. M. \& Delfino, J. J. Dissolution rates of three high explosive compounds: TNT, RDX, and HMX. Chemosphere 47, 725-734 (2002).

16. Lynch, J. C., Myers, K. F., Brannon, J. M. \& Delfino, J. J. Effects of $\mathrm{pH}$ and Temperature on the Aqueous Solubility and Dissolution Rate of 2,4,6-Trinitrotoluene (TNT), Hexahydro-1,3,5-trinitro1,3,5-triazine (RDX), and Octahydro-1,3,5,7-tetranitro-1,3,5,7-tetrazocine (HMX). J. Chem. Eng. 
478

479

480

17. Brannon, J. M., Price, C. B., Yost, S. L., Hayes, C. A. \& Porter, B. E. Comparison of environmental fate and transport process descriptors of explosives in saline and freshwater systems. Mar. Pollut. Bull. 50, 247-251 (2005).

18. Lever, J. H., Taylor, S., Perovich, L., Bjella, K. \& Packer, B. Dissolution of composition B detonation residuals. Environ. Sci. Technol. 39, 8803-8811 (2005).

19. Monteil-Rivera, F., Deschamps, S., Ampleman, G., Thiboutot, S. \& Hawari, J. Dissolution of a new explosive formulation containing TNT and HMX: Comparison with octol. J. Hazard. Mater. 174, 281-288 (2010).

20. Dontsova, K. M., Yost, S. L., Šimunek, J., Pennington, J. C. \& Williford, C. W. Dissolution and Transport of TNT, RDX, and Composition B in Saturated Soil Columns. J. Environ. Qual. 35, 20432054 (2006).

21. Thiboutot, S., Ampleman, G., Gagnon, A., Marois, A., Jenkins, T. F., Walsh, M. E., Thome, P. G. \& Ranney, T. Characterization Of Antitank Firing Ranges At CFB Valcartier, WATC Wainwright And CFAD Dundurn (DREV - R - 9809). (1998).

22. Fuller, M. E., Schaefer, C. E., Andaya, C. \& Fallis, S. Production of particulate Composition B during simulated weathering of larger detonation residues. J. Hazard. Mater. 283, 1-6 (2015).

23. Wang, P.-F., George, R. D., Wild, W. \& Liao, Q. Defining Munition Constituent (MC) Source Terms in Aquatic Environments on DoD Ranges (ER-1453). Technical Report 1999 (2013).

24. Wang, P.-F., Liao, Q., George, R. \& Wild, W. Release rate and transport of munitions constituents from breached shells in marine environment. ACS Symp. Ser. 1069, 317-340 (2011). 
498 25. Brannon, J. M. \& Pennington, J. C. Environmental Fate and Transport Process Descriptors for Explosives. Strateg. Environ. Res. Dev. Progr. Install. Restor. Res. Progr. ERDC/ELTR-02-10 (2002).

26. Luning Prak, D. J. \& O'Sullivan, D. W. Solubility of 2,4-Dinitrotoluene and 2,4,6-Trinitrotoluene in Seawater. J. Chem. Eng. Data 51, 448-450 (2006).

27. Frenz, U. Autonome Unterwasserfahrzeuge mit SAS-Technologie. Lehre und Forsch. 02-2014, 11503 16 (2014).

28. Pfeiffer, F. Bericht über die in-situ-Begleituntersuchungen zur Munitionssprengung in der Ostsee vom 18.2.2009 (Ausschreibungsnummer: 4123-2009-41F). (2009). at <https://www.schleswigholstein.de/DE/Fachinhalte/M/meeresschutz/Downloads/Bericht_Begleituntersuchung_2009.pdf ?_blob=publicationFile \&v=1>

29. Pfeiffer, F. Bericht über die in-situ-Begleituntersuchungen zur Munitionssprengung in der Ostsee vom 28.2. - 18.3.2012 (Ausschreibungsnummer: ZB-U0-12-0027000-4121.6). (2012). at $<$ https://www.schleswig-

513 30. Pfeiffer, F. Bericht über Zusammensetzung und Eigenschaften einer Schießwolleprobe holstein.de/DE/Fachinhalte/M/meeresschutz/Downloads/Bericht_Heidkate.pdf?_blob=publicati onFile \&v=1>

31. Szala, M. 2nd DAIMON Meeting Goslar, Germany 17-19th October 2016. (2016). (Vergabenummer: ZB-50-14-0292000-4121.7). 1-26 (2014). at <https://www.schleswigholstein.de/DE/Fachinhalte/M/meeresschutz/Downloads/Bericht_Heidkate.pdf?_blob=publicati onfile \&v=1>

32. Radtke, H., Lipka, M., Bunke, D., Morys, C., Woelfel, J., Cahill, B., Böttcher, M. E., Forster, S., Leipe, T., Rehder, G. \& Neumann, T. Ecological ReGional Ocean Model with vertically resolved sediments 
(ERGOM SED 1.0): coupling benthic and pelagic biogeochemistry of the south-western Baltic Sea. Geosci. Model Dev. 12, 275-320 (2019).

33. Gledhill, M., Beck, A. J., Stamer, B., Schlosser, C. \& Achterberg, E. P. Quantification of munition compounds in the marine environment by solid phase extraction - ultra high performance liquid chromatography with detection by electrospray ionisation - mass spectrometry. Talanta 200, 366-372 (2019).

34. Schlosser, C., Streu, P., Frank, M., Lavik, G., Croot, P. L., Dengler, M. \& Achterberg, E. P. H2S Rep. 8, 1-8 (2018).

35. Mohrholz, V., Naumann, M., Nausch, G., Krüger, S. \& Gräwe, U. Fresh oxygen for the Baltic Sea An exceptional saline inflow after a decade of stagnation. J. Mar. Syst. 148, 152-166 (2015).

36. Gräwe, U., Friedland, R. \& Burchard, H. The future of the western Baltic Sea: Two possible scenarios. Ocean Dyn. 63, 901-921 (2013).

37. Klingbeil, K., Mohammadi-Aragh, M., Gräwe, U. \& Burchard, H. Quantification of spurious dissipation and mixing - Discrete variance decay in a finite-Volume framework. Ocean Model. 81,

38. Thorpe, S. A. The Turbulent Ocean. (Cambridge University Press, 2005).

39. Holtermann, P. L., Umlauf, L., Tanhua, T., Schmale, O., Rehder, G. \& Waniek, J. J. The Baltic Sea Tracer Release Experiment: 1. Mixing rates. J. Geophys. Res. Ocean. 117, 1-18 (2012). 2257-2267 (2018). 
542 41. Beck, A. J., Gledhill, M., Schlosser, C., Stamer, B., Böttcher, C., Sternheim, J., Greinert, J. \&

42. CRANK, J., McFARLANE, N. R., NEWBY, J. C., PATERSON, G. D. \& PEDLEY, J. B. Diffusion Processes in Environmental Systems. (TRE MACMILLAN PRESS LTD, 1981). doi:10.1007/978-1-349-05825-9

43. Haas, R. \& Thieme, J. Band 2 : Explosivstofflexikon. Bestandsaufnahme von Rüstungsaltlastverdachtsstandorten der Bundesrepublik Deutschland, 2. Erweiterte Auflage, Umweltbundesamt [Inventory suspected armament Contam. sites Fed. Repub. Ger. Second Ext. Ed. Fed. Envi 378 pp. (1996). at <https://www.umweltbundesamt.de/en/publikationen/bestandsaufnahme-von-1>

44. Morley, M. C., Yamamoto, H., Speitel, G. E. \& Clausen, J. Dissolution kinetics of high explosives particles in a saturated sandy soil. J. Contam. Hydrol. 85, 141-158 (2006).

45. Lynch, J. C. Dissolution Kinetics of High Explosive Compounds (TNT, RDX, HMX). ERDC/EL Rep. TR-

46. Phelan, J. M., Romero, J. V, Barnett, J. L. \& Parker, D. R. Solubility and dissolution kinetics of 02-23. 1-133 (2002).

47. Baytos, J. F. LASL explosive property data (Vol. 4). (Univ of California Press, 1980).

408, 3536-3553 (2010). 